\title{
Evaluation of the Prognostic Stage in the 8th Edition of the American Joint Committee on Cancer in Patients with Breast Cancer and Internal Mammary Lymph Node Metastasis
}

\author{
JI HYEON JOO ${ }^{1}$, SU SSAN KIM ${ }^{2}$, BYUNG HO SON ${ }^{3}$, SEUNG DO AHN ${ }^{2}$, JIN HONG JUNG ${ }^{2}$, \\ EUN KYUNG CHOI ${ }^{2}$, SEI HYUN AHN ${ }^{3}$, JONG WON LEE ${ }^{3}$, HEE JUNG KIM ${ }^{3}$ and BEOM SEOK KO ${ }^{3}$ \\ ${ }^{1}$ Department of Radiation Oncology, Ajou University School of Medicine, Suwon, Republic of Korea; \\ Departments of ${ }^{2}$ Radiation Oncology and ${ }^{3}$ Breast and Endocrine Surgery, Asan Medical Center, \\ University of Ulsan College of Medicine, Seoul, Republic of Korea
}

\begin{abstract}
Background/Aim: This study evaluated the prognostic value of the 8th edition of American Joint Committee on Cancer (AJCC) cancer staging system for patients with internal mammary lymph node (IMN) metastases. Materials and Methods: Of the patients with breast cancer who were treated between 2009 and 2013, 66 were diagnosed as $c N 3 b$. We restaged the patients and analyzed the prognostic value of the prognostically staged groups. Results: With a median follow-up of 53.9 months, the 5-year overall survival rates of patients with IIIA, IIIB, and IIIC stages were $100 \%, 95 \%$, and $50 \%(p=0.001)$, while the progression-free survival rates were $100 \%, 83 \%$, and $50 \%$ $(p=0.005)$. Conclusion: Despite the small number of patients, the prognostic stage provided accurate information for IMN metastasized breast cancer, which will lead to more accurate prognosis predictions and optimal treatment selection.
\end{abstract}

After development of the American Joint Committee on Cancer (AJCC) staging system in the 1970s, the system was updated every few years, reflecting the most important factors predicting survival. The new "prognostic stage" in the 8th edition of the AJCC staging system incorporates important biological factors, such as estrogen receptor (ER), progesterone receptor (PR), human epidermal growth factor receptor-2 (HER2), histological grade, and TNM stage into one system (1). This approach requires further validation,

Correspondence to: Su Ssan Kim, MD, Ph.D., Department of Radiation Oncology, Asan Medical Center, University of Ulsan College of Medicine, 88, Olympic-ro 43-gil, Songpa-Gu, Seoul, 05505, Republic of Korea. Tel: +82 230105680, Fax: +82 230106950, e-mail: watermountain@hanmail.net

Key Words: Breast neoplasms, internal mammary lymph nodes, AJCC cancer staging, neoplasm metastases, survival. when considering the complexity of clinical use caused by a new staging system. Several validation studies from large populations of patients have demonstrated the accuracy of the new staging system $(2,3)$, including for patients with advanced breast cancer (4).

The tumor and patient characteristics of internal mammary lymph node (IMN)-positive breast cancer differ from locally advanced breast cancer without IMN metastasis (5). Studies have clearly shown that patients with IMN involvement have a worse prognosis that is associated with higher rates of distant disease and lower overall survival (OS) (6). Thus, the consensus discussion on the detection and treatment of IMN metastasis continues $(5,7)$. Therefore, we first verified the predictability of the new staging system in these patients. This retrospective study evaluated the prognostic value of the 8th edition of AJCC cancer staging system for patients with IMN metastasis.

\section{Materials and Methods}

Patients. Our Institutional Review Board approved the retrospective use of clinical data. Of the patients who were treated with neoadjuvant chemotherapy, surgery, and radiotherapy (RT) in our institution between 2009 and 2013, 114 women had suspicious IMNs either by size and morphology or by 18F-fluorodeoxyglucose (FDG) avidity. After all examinations, clinical IMN metastasis was diagnosed by a positive 18F-FDG positron emission tomography with a computed tomography (PET/CT) scan or pathological confirmation, either with $(\mathrm{cN} 3 b)$ or without $(\mathrm{cN} 2 \mathrm{~b})$ axillary lymph node metastasis. The details of this treatment have been described previously (7). All patients received external beam RT targeting the breast or chest wall and/or regional lymphatics, including the ipsilateral axillary apex, supraclavicular fossa, and IMN compartment.

Statistics. All clinicopathological data were retrieved from the electronic medical recording system, including histological and nuclear grades, hormone receptor status, and HER2 status of the primary tumor. Locoregional recurrence included ipsilateral breast, chest wall, axillary, supraclavicular, or IMN. Distant failure was 
Table I. Patient characteristics.

\begin{tabular}{|c|c|c|c|c|c|}
\hline \multirow[b]{2}{*}{ Variables } & \multirow{2}{*}{$\begin{array}{l}\mathrm{N}(\%) \\
\text { Total }\end{array}$} & \multicolumn{3}{|c|}{$\mathrm{N}$} & \multirow[t]{2}{*}{$p$-Value } \\
\hline & & IIIA & IIIB & IIIC & \\
\hline Age (median, years) & $45.1 \pm 10.6$ & 42.0 & 47.3 & 42.2 & 0.151 \\
\hline Body mass index (median) & $23.2 \pm 3.4$ & 25.8 & 23.1 & 23.0 & 0.554 \\
\hline \multicolumn{6}{|l|}{ Laterality } \\
\hline Rt & $26(39)$ & 0 & 15 & 11 & \multirow[t]{2}{*}{0.498} \\
\hline $\mathrm{Lt}$ & $40(41)$ & 2 & 23 & 15 & \\
\hline \multicolumn{6}{|l|}{ Clinical $\mathrm{T}$ category } \\
\hline $\mathrm{T} 1-2$ & $42(54)$ & 1 & 25 & 16 & \multirow[t]{2}{*}{0.393} \\
\hline $\mathrm{T} 3$ & $24(36)$ & 1 & 13 & 10 & \\
\hline $\mathrm{SUV}_{\max }$ & $3.1 \pm 2.4$ & 3.0 & 3.1 & 3.1 & 0.997 \\
\hline \multicolumn{6}{|l|}{ Breast surgery } \\
\hline BCS & $29(44)$ & 0 & 16 & 13 & \multirow[t]{2}{*}{0.367} \\
\hline MRM & $37(56)$ & 2 & 22 & 13 & \\
\hline \multicolumn{6}{|l|}{ Axillary surgery } \\
\hline ALND & $53(80)$ & 1 & 33 & 19 & \multirow[t]{2}{*}{0.218} \\
\hline SLNB & $13(20)$ & 1 & 5 & 7 & \\
\hline \multicolumn{6}{|l|}{ Estrogen receptor } \\
\hline Negative & $36(55)$ & 0 & 12 & 24 & \multirow[t]{2}{*}{0.000} \\
\hline Positive & $30(45)$ & 2 & 26 & 2 & \\
\hline \multicolumn{6}{|l|}{ Progesterone receptor } \\
\hline Negative & $46(70)$ & 0 & 20 & 26 & \multirow[t]{2}{*}{0.000} \\
\hline Positive & $20(30)$ & 2 & 18 & 0 & \\
\hline \multicolumn{6}{|l|}{ HER2 } \\
\hline Negative & $45(68)$ & 0 & 19 & 26 & \multirow[t]{2}{*}{0.000} \\
\hline Positive & $21(32)$ & 2 & 19 & 0 & \\
\hline \multicolumn{6}{|l|}{ Histologic grade } \\
\hline $2 / 3$ & $29(44)$ & 2 & 22 & 5 & \multirow[t]{2}{*}{0.002} \\
\hline $3 / 3$ & $37(56)$ & 0 & 16 & 21 & \\
\hline \multicolumn{6}{|l|}{ ypT-stage } \\
\hline 0 or 1 & $37(56)$ & 0 & 21 & 16 & \multirow[t]{2}{*}{0.237} \\
\hline 2 or 3 & $29(44)$ & 2 & 17 & 10 & \\
\hline \multicolumn{6}{|l|}{ ypN-stage } \\
\hline 0 or 1 & $47(71)$ & 1 & 27 & 19 & 0.827 \\
\hline 2 or 3 & $19(29)$ & 1 & 11 & 7 & \\
\hline Adjuvant trastuzumab & & & & & \\
\hline No & $45(68)$ & 0 & 19 & 26 & 0.000 \\
\hline Yes & $21(32)$ & 2 & 19 & 0 & \\
\hline Hormone therapy & & & & & \\
\hline No & $34(52)$ & 0 & 10 & 24 & 0.000 \\
\hline Yes & $32(48)$ & 2 & 28 & 2 & \\
\hline RT to SCL & & & & & \\
\hline No & $1(1)$ & 0 & 1 & 0 & 0.688 \\
\hline Yes & 65 (99) & 2 & 37 & 26 & \\
\hline RT to IMN & & & & & \\
\hline No & $5(8)$ & 0 & 5 & 0 & 0.136 \\
\hline Yes & $61(92)$ & 2 & 33 & 26 & \\
\hline
\end{tabular}

SUVmax: Maximum standardized uptake value; BCS: breast-conserving surgery; MRM: modified radical mastectomy; ALND: axillary lymph node dissection; SLNB: sentinel lymph node biopsy; HER2: human epidermal growth factor receptor 2; RT: radiation therapy; SCL: supraclavicular lymph node; IMN: internal mammary lymph node.

defined as recurrence away from local and regional sites. Diseasefree status was defined as no evidence of local failure, regional failure, distant failure, or death. Locoregional recurrence-free survival (LRRFS), distant metastasis-free survival (DMFS), progression-free survival (PFS), and OS were calculated using the Kaplan-Meier method, and comparisons between the groups were made using the log-rank test. A multivariate analysis was performed using the Cox proportional hazards model. All analyses were twosided, and a $p$-value $<0.05$ was considered significant. All statistical analyses were performed using $\mathrm{R}$ software (8).

\section{Results}

Patients. Seventy-four patients with breast cancer had IMN metastases and were treated with neoadjuvant chemotherapy, surgery, and adjuvant RT during the inclusion period. Of them, patients with inflammation of bilateral breast cancer $(\mathrm{N}=4)$ and patients with solitary IMN metastases without axillary $\mathrm{LN}$ metastases $(\mathrm{N}=4)$ were excluded. The median age of the cohort was 45 years old. Clinical T stage was T1-2 in 42 (54\%) patients and T3 in 24 (36\%) patients. ER, PR, and HER2 status was positive in $30(45 \%), 20(30 \%)$, and 21 (32\%) cases, respectively. Adjuvant trastuzumab and hormone therapy was used in $21(32 \%)$ and $32(48 \%)$ patients. RT to the supraclavicular and IMN was used in $32(48 \%)$ and 61 (92\%) cases, respectively. The patient and tumor characteristics are summarized in Table I.

According to the anatomical stage, $\mathrm{N} 3 \mathrm{~b}$ patients were staged as IIIC, regardless of the T stage. These patients were separated into three stages of IIIA $(\mathrm{N}=2,3 \%)$, IIIB $(\mathrm{N}=38$, $58 \%)$, and IIIC ( $\mathrm{N}=26,39 \%)$ according to their prognostic stage. Thus, $61 \%$ had their stage reassigned and downstaged.

Survival outcomes among the prognostic stages. With a median follow up of 53.9 months (interquartile range $=39-66$ months), the OS, PFS, LRRFS, and DMFS rates at 5 years were $77 \%, 70 \%, 81 \%$, and $72 \%$, respectively (Figure 1). According to the Cox multivariate analysis, hormone receptor status and ypN-stage were independent prognostic factors for OS and DFS (Table II). Hormone receptor status, lympho-vascular space invasion, and ypN-stage were independent prognostic factors for DMFS (Table III).

The prognostic stage incorporates anatomical factors and biological factors into one system. When patients with IMNpositive breast cancer were stratified based on prognostic stage, significant differences were observed in the OS, PFS, LRRFS and DMFS rates. The 5-year OS rates of patients with IIIA, IIIB, and IIIC were $100 \%, 95 \%$, and $50 \%(p=0.001)$, while the PFS rates were $100 \%, 83 \%$, and $50 \%(p=0.005)$. The 5-year LRRFS rates of patients with IIIA, IIIB, and IIIC were $100 \%, 92 \%$, and $63 \%(p=0.013)$, while the DMFS rates were $100 \%, 83 \%$, and $54 \%$, respectively $(p=0.013)$. The survival graphs are shown in Figure 2. The difference between stage IIIB and IIIC was significant: OS, hazard ratio (HR) of IIIC ( $v s$. IIIB) $=1.997(p=0.002)$; DFS, HR=1.441 $(p=0.004)$; LRRFS, HR=5.536 $(p=0.01)$; DMFS, HR=3.752 $(p=0.006)$, according to the Cox-regression model. 
os

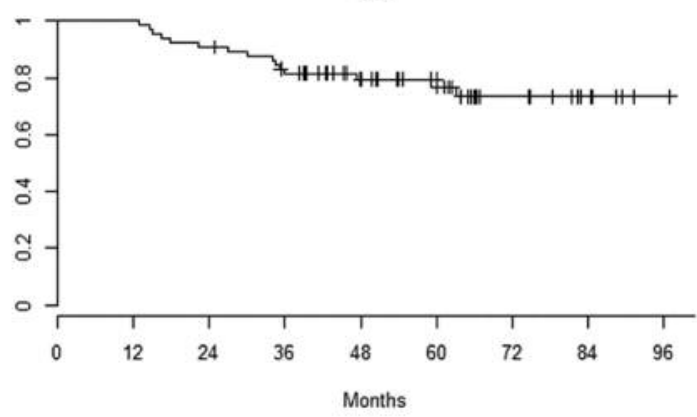

LRRFS

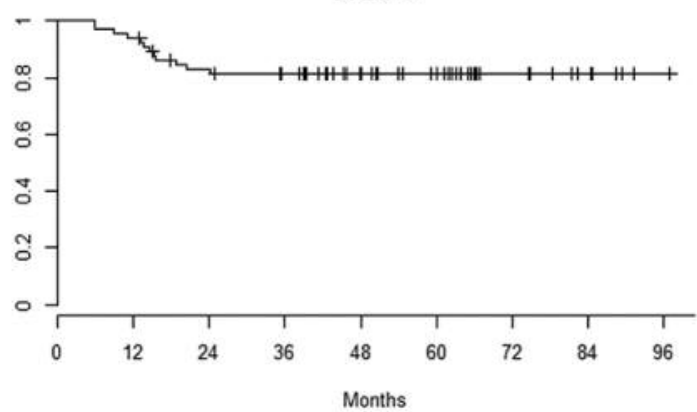

PFS

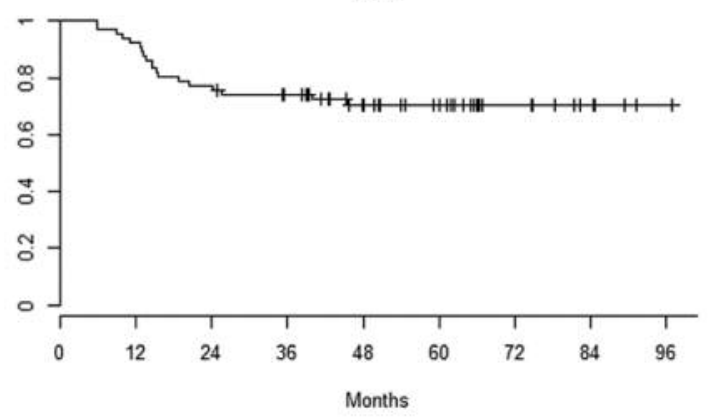

DMFS

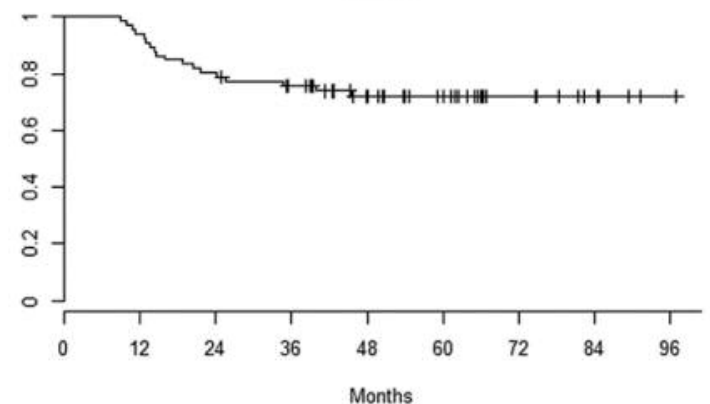

Figure 1. Kaplan-Meier survival curves of the total patients. OS: Overall survival; PFS: progression-free survival; LRRFS: locoregional recurrencefree survival; DMFS: distant metastasis-free survival.

os

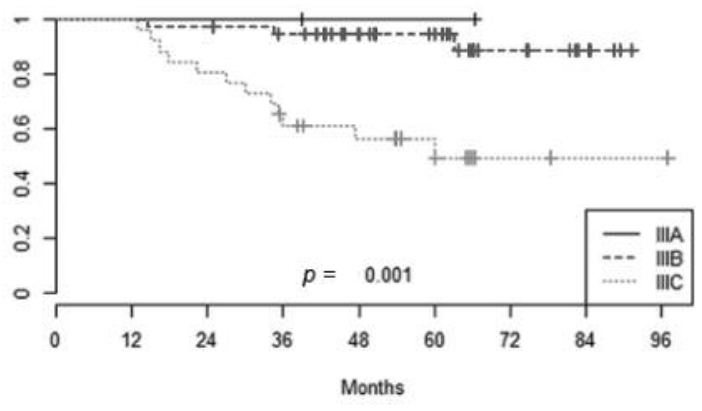

LRRFS



PFS

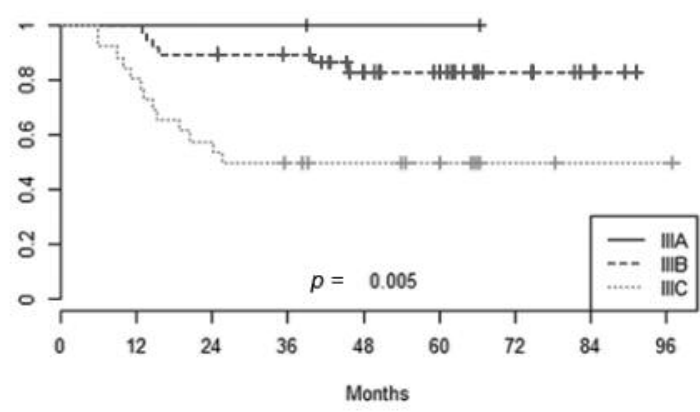

DMFS

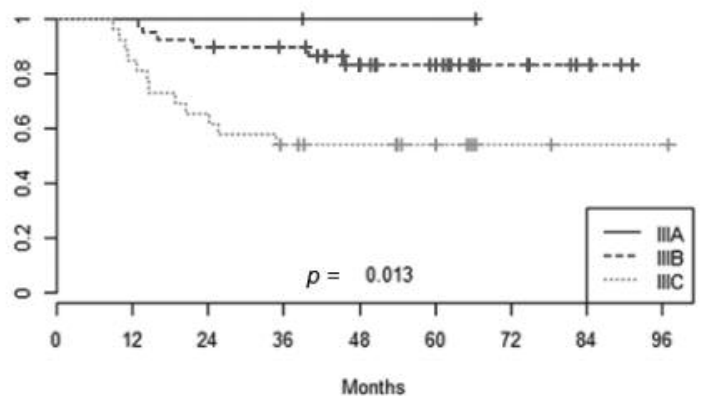

Figure 2. Survival curves according to different stages using the 8th edition of the AJCC prognostic staging system. OS: Overall survival; PFS: progression-free survival; LRRFS: locoregional recurrence-free survival; DMFS: distant metastasis-free survival. 
Table II. Univariate and multivariate analysis for OS, PFS.

\begin{tabular}{|c|c|c|c|c|}
\hline & \multicolumn{2}{|c|}{ OS } & \multicolumn{2}{|c|}{ PFS } \\
\hline & Univariate & Multivariate & Univariate & Multivariate \\
\hline Lt breast & $1.24(0.45-3.43)$ & & $1.35(0.55-3.32)$ & \\
\hline $\mathrm{BMI} \geq 23$ & $0.61(0.21-1.78)$ & & $0.42(0.15-1.16)$ & $0.42(0.15-1.19)$ \\
\hline cT3 (vs. T1-2) & $0.61(0.19-1.92)$ & & $0.6(0.21-1.66)$ & \\
\hline Histologic grade 3 & $3.54(1-12.55)$ & & $2.68(0.97-7.46)$ & \\
\hline MRM & $1.75(0.6-5.11)$ & & $1.53(0.6-3.9)$ & \\
\hline Hormone receptor+ & $0.07 *(0.01-0.52)$ & $0.05^{*}(0.01-0.40)$ & $0.17 *(0.05-0.58)$ & $0.08 *(0.02-0.28)$ \\
\hline HER2-positive & $0.5(0.14-1.77)$ & & $0.53(0.17-1.59)$ & \\
\hline $\mathrm{Ki} 67 \geq 70$ & $1.55(0.56-4.28)$ & & $1.66(0.674 .08)$ & \\
\hline LVI & $1.55(0.56-4.27)$ & & $2.63 *(1.04-6.71)$ & $5.74 *(2.12-15.52)$ \\
\hline ypN2/3 (vs. 0/1) & $2.52(0.91-6.96)$ & $3.93^{*}(1.40-11.03)$ & $2.61 *(1.06-6.44)$ & \\
\hline Adjuvant trastuzumab & $0.5(0.14-1.77)$ & & $0.53(0.17-1.59)$ & \\
\hline Hormone therapy & $0.13 *(0.03-0.56)$ & & $0.22 *(0.07-0.65)$ & \\
\hline
\end{tabular}

OS: Overall survival; PFS: progression-free survival; *Statistically significant values.

Table III. Univariate and multivariate analysis for LRRFS, DMFS.

\begin{tabular}{|c|c|c|c|c|}
\hline & \multicolumn{2}{|c|}{ LRRFS } & \multicolumn{2}{|c|}{ DMFS } \\
\hline & Univariate & Multivariate & Univariate & Multivariate \\
\hline Lt breast & $2.15(0.68-6.78)$ & & $1.52(0.6-3.82)$ & \\
\hline $\mathrm{BMI} \geq 23$ & $0.61(0.18-2.04)$ & & $0.46(0.16-1.29)$ & \\
\hline cT3 (vs. T1-2) & $0.57(0.15-2.09)$ & & $0.66(0.24-1.85)$ & \\
\hline Histologic grade 3 & $4.57(1-20.87)$ & $3.05(0.69-14.46)$ & $2.4(0.86-6.75)$ & \\
\hline MRM & $1.2(0.38-3.78)$ & & $1.84(0.69-4.91)$ & \\
\hline Hormone receptor+ & $<0.01 *$ & & $0.18 *(0.05-0.64)$ & $0.11 *(0.03-0.38)$ \\
\hline HER2-positive & $0.66(0.18-2.44)$ & & $0.57(0.19-1.74)$ & \\
\hline $\mathrm{Ki} 67 \geq 70$ & $1.99(0.63-6.28)$ & & $1.89(0.74-4.78)$ & \\
\hline LVI & $1.01(0.32-3.2)$ & & $2.31(0.89-5.96)$ & $2.93 *(0.02-8.45)$ \\
\hline ypN2/3 (vs. 0/1) & $1.4(0.42-4.67)$ & & $3 *(1.19-7.57)$ & $3.02 *(1.08-8.42)$ \\
\hline Adjuvant trastuzumab & $0.66(0.18-2.44)$ & & $0.57(0.19-1.74)$ & \\
\hline Hormone therapy & $<0.01 *$ & & $0.24 *(0.08-0.73)$ & \\
\hline
\end{tabular}

LRRFS: Locoregional recurrence-free survival; DMFS: distant metastasis-free survival; BMI: body mass index; *Statistically significant values.

\section{Discussion}

In our study, we analyzed the clinical significance of the prognostic staging system proposed in the 8th edition of the AJCC cancer staging system for breast cancer with IMN metastases. A total of 66 patients with N3c disease were included. The prognostic stage system screened out $61 \%$ of the patients with relatively better survival outcomes from IIIC and they were grouped into IIIA or IIIB. Patients with stage IIIC were more likely to have recurrence and death in the long-term. The risk of recurrence or death was about double compared to patients in stage IIIB. The current analysis showed an improvement in the discriminatory value for the prognostic staging system compared to the anatomical staging system.
Pathological nodal staging of IMNs has changed over time. In the past, all IMN metastases were classified as pN3, because IMNs were considered of great importance in formulating the prognosis of patients (9). After the introduction of the detection technique and sentinel lymph node biopsy, IMN metastases were divided into $\mathrm{pN} 1 \mathrm{~b}, \mathrm{pN} 1 \mathrm{c}$, $\mathrm{pN} 2 \mathrm{~b}$, or $\mathrm{pN} 3 \mathrm{~b}$ status. IMN metastases are no longer considered to have a dismal prognosis. One of the largest retrospective reports came from Zhang et al. (5). Ninety-six patients who were clinically IMN metastasis-positive received neoadjuvant chemotherapy, surgery, and adjuvant radiation, including the IMN region. The actuarial 5-year locoregional control, DFS, and OS rates were $80 \%, 60 \%$, and $79 \%$, respectively (5). Another study assessed the outcomes 
of patients diagnosed with $\mathrm{cN} 3$ disease identified by PET. Of the 12 patients with $\mathrm{cN} 3 \mathrm{~b}$ disease, LRRFS was $83 \%$, and DFS was $67 \%$ (10). A DFS rate of $87 \%$ was reported when low-tumor burden IMN metastases were treated using a multimodal treatment, even in patients who were mostly staged as $\mathrm{cN} 3 \mathrm{~b}$ (7). Therefore, patients diagnosed as N3b are potentially curable, and it is necessary to tailor their intensive treatment. Thus, an accurate prognostic judgement is required as demonstrated by using the AJCC 8th edition.

Tumor burden and biology are considered equally in the era of personalized care. A new "prognostic stage" that included ER, PR, HER2, histological grade, and conventional TNM variables into one staging system was added to the 8 th edition. As the staging system has been gradually changed and subdivided, the stages were re-evaluated differently, even though the pathological findings did not change. Weiss et al. analyzed more than 50,000 patients from the California Cancer Registry with stage I-IV breast cancer treated between 2005 and 2009. The prognostic stage re-staged $51.6 \%$ of the patients. The prognostic stage (C index by Harrell concordance index, 0.8426) provided more accurate stratification with respect to disease-specific survival than the anatomic stage ( $\mathrm{C}$ index, 0.8097) (3). The prognostic stage enabled a clearer classification of survival according to disease stage subtype than that observed using the anatomic stage. In previous staging, some subgroups of patients with lower stage disease had lower survival rates than that of patients with a higher stage and better subtype disease. Thus, it has been argued that the intrinsic subtype of breast cancer has an equal or greater prognostic impact in predicting clinical outcomes (11). Lee et al. reported that the survival rate of patients with stage II hormone receptor $(\mathrm{HR})(+) / \mathrm{HER} 2(-)$ disease is superior to that of patients with stage I HR(-)/HER(-) disease. Also, the survival rate of patients with stage III HR(+)/HER2(-) disease was better than those with stage II HR(-)/HER2(-) disease. However, the overlap of the survival curves disappeared when using the prognostic stage (2).

\section{Conclusion}

Despite the small number of patients, the prognostic stage provided accurate prognostic information for IMN metastasized breast cancer. This staging will lead to greater accuracy in the prognosis prediction and optimal treatment selection, and, therefore, better outcomes.

\section{References}

1 Amin MB, Greene FL, Edge SB, Compton CC, Gershenwald JE, Brookland RK, Meyer L, Gress DM, Byrd DR and Winchester DP: The eighth edition AJCC cancer staging manual: continuing to build a bridge from a population-based to a more "personalized" approach to cancer staging. CA Cancer J Clin 67: 93-99, 2017.
2 Lee SB, Sohn G, Kim J, Chung IY, Lee JW, Kim HJ, Ko BS, Son $\mathrm{BH}$ and Ahn $\mathrm{SH}$ : A retrospective prognostic evaluation analysis using the 8th edition of the American Joint Committee on Cancer staging system for breast cancer. Breast Cancer Res Treat 169: 257-266, 2018.

3 Weiss A, Chavez-MacGregor M, Lichtensztajn DY, Yi M, Tadros A, Hortobagyi GN, Giordano SH, Hunt KK and Mittendorf EA: Validation study of the American Joint Committee on cancer eighth edition prognostic stage compared with the anatomic stage in breast cancer. JAMA Oncol 4: 203-209, 2018.

4 Wang M, Chen $\mathrm{H}$, Wu K, Ding A, Zhang M and Zhang P: Evaluation of the prognostic stage in the 8th edition of the American Joint Committee on Cancer in locally advanced breast cancer: an analysis based on SEER 18 database. Breast 37: 5663, 2018.

5 Zhang YJ, Oh JL, Whitman GJ, Iyengar P, Yu TK, Tereffe W, Woodward WA, Perkins G, Buchholz TA and Strom EA: Clinically apparent internal mammary nodal metastasis in patients with advanced breast cancer: incidence and local control. Int J Radiat Oncol Biol Phys 77: 1113-1119, 2010.

6 Sugg SL, Ferguson DJ, Posner MC and Heimann R: Should internal mammary nodes be sampled in the sentinel lymph node era? Ann Surg Oncol 7: 188-192, 2000.

7 Joo JH, Kim SS, Ahn SD, Choi EK, Jung JH, Jeong Y, Ahn $\mathrm{SH}$, Son BH, Lee JW, Kim HJ, Go BS, Kim HH, Cha JH, Shin $\mathrm{HJ}$ and Chae EY: Impact of pathologic diagnosis of internal mammary lymph node metastasis in clinical N2b and N3b breast cancer patients. Breast Cancer Res Treat 166: 511-518, 2017.

8 R Development Core Team: R: A language and Environment for the Statistical Computing, $\mathrm{R}$ Foundation for Statistical Computing. Vienna, Austria: the R Foundation for Statistical Computing; 2017. https://www.r-project.org/.

9 Sobin LH and Fleming ID: TNM Classification of Malignant Tumors, fifth edition (1997). Union Internationale Contre le Cancer and the American Joint Committee on Cancer. Cancer 80: 1803-1804, 1997.

10 Park HJ, Shin KH, Cho KH, Park IH, Lee KS, Ro J, Jung SY, Lee S, Kim SW, Kang HS, Chie EK and Ha SW: Outcomes of positron emission tomography-staged clinical N3 breast cancer treated with neoadjuvant chemotherapy, surgery, and radiotherapy. Int J Radiat Oncol Biol Phys 81: e689-695, 2011.

11 Jung HA, Park YH, Kim M, Kim S, Chang WJ, Choi MK, Hong JY, Kim SW, Kil WH, Lee JE, Nam SJ, Ahn JS and Im YH: Prognostic relevance of biological subtype overrides that of TNM staging in breast cancer: discordance between stage and biology. Tumour Biol 36: 1073-1079, 2015.
Received July 3, 2018

Revised July 24, 2018

Accepted July 25, 2018 